\title{
Characterisation of PMMA/ATH Layers Realised by Means of Atmospheric Pressure Plasma Powder Deposition
}

\author{
Lena M. Wallenhorst, ${ }^{1}$ Sebastian Dahle, ${ }^{2,3}$ Matej Vovk, ${ }^{4,5}$ Lisa Wurlitzer, ${ }^{2,3}$ \\ Leander Loewenthal, ${ }^{1}$ Nils Mainusch, ${ }^{6}$ Christoph Gerhard, ${ }^{6}$ and Wolfgang Viöl ${ }^{1,6}$ \\ ${ }^{1}$ Laboratory of Laser and Plasma Technologies, University of Applied Sciences and Arts, Von-Ossietzky-Straße 99, \\ 37085 Göttingen, Germany \\ ${ }^{2}$ Institute of Energy Research and Physical Technologies, Clausthal University of Technology, Leibnizstraße 4, \\ 38678 Clausthal-Zellerfeld, Germany \\ ${ }^{3}$ Clausthal Center of Material Technology (CZM), Clausthal University of Technology, Agricolastraße 2, \\ 38678 Clausthal-Zellerfeld, Germany \\ ${ }^{4}$ Biotechnical Faculty, University of Ljubljana, Jamnikarjeva 101, Sl-1000 Ljubljana, Slovenia \\ ${ }^{5}$ Kolpa d.d., Rosalnice 5, Sl-8330 Metlika, Slovenia \\ ${ }^{6}$ Application Center for Plasma and Photonics, Fraunhofer Institute for Surface Engineering and Thin Films, \\ Von-Ossietzky-Straße 100, 37085 Göttingen, Germany \\ Correspondence should be addressed to Sebastian Dahle; s.dahle@pe.tu-clausthal.de
}

Received 7 May 2015; Accepted 2 July 2015

Academic Editor: Charles Rosenblatt

Copyright ( 2015 Lena M. Wallenhorst et al. This is an open access article distributed under the Creative Commons Attribution License, which permits unrestricted use, distribution, and reproduction in any medium, provided the original work is properly cited.

We report on the characteristics of aluminium trihydrate filled poly(methyl methacrylate) composite (PMMA/ATH) coatings realised by plasma deposition at atmospheric pressure. For this purpose, PMMA/ATH powder was fed to a plasma jet where the process and carrier gas was compressed air. The deposited coatings were investigated by X-ray photoelectron spectroscopy and water contact angle measurements. Further, the raw material was characterised before deposition. It was found that, with respect to the raw material, aluminium was uncovered in the course of the plasma deposition process which can be explained by plasmainduced etching of the PMMA matrix. As a result, the wettability of plasma-deposited PMMA/ATH was significantly increased. Even though a uniform coating film could not be realised as ascertained by confocal laser scanning microscopy, the deposited coatings feature notably enhanced characteristics which could be advantageous for further processing.

\section{Introduction}

The application of inorganic fillers as reinforcement within polymer composites is a well-known approach [1] that is still commonly applied [2]. One particular composite material that has been continuously improved in the past decades and is still having an increasing number of applications is poly(methyl methacrylate) (PMMA) reinforced with aluminium trihydrate $\left(\mathrm{Al}(\mathrm{OH})_{3}, \mathrm{ATH}\right)$. The PMMA/ATH composite is classified as solid material [3] and was developed and described by Duggins and coworkers $[4,5]$. Several different compositions and fabrication processes are commonly in use, but in general PMMA/ATH composites consist of about $40 \%$
PMMA and 60\% ATH. All composites of this kind feature high moisture resistance, good chemical resistance, and UV resistance. They are safe for food contact, easy to clean, and thermoformable $[6,7]$. The ATH used as inorganic filler within the composite lowers the costs for the fabrication of this material and further drastically improves the mechanical properties such as elastic modulus [8], abrasion, and wear resistance [9] as well as the fatigue life [10]. The ATH also acts as a flame retardant and smoke suppressant [11-13].

For many applications, ATH filler particles with average sizes of approximately $2-10 \mu \mathrm{m}$ are used, which typically occur as agglomerates of $40-50 \mu \mathrm{m}$ [14]. Otherwise, bead milling can be used to ensure an average filler particle size 
below $1 \mu \mathrm{m}$, consequently improving the distribution of the filler particles within the matrix [15]. Furthermore, silane coupling agents [16] are usually applied to ensure an excellent dispersion [15] and enhance the mechanical properties $[9,10]$ as well as the thermal stability of the composite material [15].

However, the final processing of PMMA/ATH composite materials may be complicated. For example, it has been found to be quite challenging to form a structural joint via bonding of PMMA/ATH material with wood and wood composites [17]. Another open issue is the recycling of PMMA/ ATH composite materials. The shaping and polishing of PMMA/ATH work pieces produce an estimated amount of 1200 tons of PMMA/ATH waste dust per year only in Slovenia [18]. Even though the material itself exhibits outstanding mechanical and chemical properties, residual powder and chips can hardly be used in an industrial and economically viable way. Kaminsky and colleagues [19] have carried out the pyrolysis of a PMMA/ATH composite. Pyrolysis of PMMA is already an established way of obtaining methyl methacrylate monomer (MMA), because at $450^{\circ} \mathrm{C}$ as much as $97.2 \%$ of MMA can be obtained. Authors investigated if it is possible to obtain similarly high proportions of MMA from PMMA/ATH composites with high content of ATH and whether there is a catalytic effect of ATH in the process of pyrolysis. The results showed that the pyrolysis of the PMMA/ATH obtained only 58\% of the MMA, which is a much smaller percentage compared to $97 \%$, which was obtained from pure PMMA. By-products of the thermal decomposition of this composite were the hydrolysis products of MMA, such as methacrylic acid, methanol, and isobutyl acid. By lowering the temperature to $400^{\circ} \mathrm{C}$, they have managed to increase the obtained MMA to $65 \%$ by weight. They found that such a low proportion of acquired MMA is a consequence of the water released from the pyrolysis of ATH and chemical stabilizers in the composite. The high proportion of aluminium components practically has no catalytic effect on hydrolysis, because they got the same results by using the water vapour as fluidising medium instead of nitrogen [19]. However, some innovative approaches recently try to make use of the waste powder, for example, as filler for bitumen [18].

In a recent approach, the use of a dielectric barrier discharge (DBD) plasma for the modification of PMMA/ATH work pieces has been evaluated, that is, trying to functionalise the PMMA/ATH surface and to improve the bonding of glues and other polymers to the modified PMMA/ATH surface. In the literature, several effects of cold plasma discharges on PMMA are reported, namely,

(a) an oxidation of the polymer [20],

(b) a homogeneous etching of the polymer [21],

(c) a generation of micro- or nanopatterns on the polymer's surface [22].

All of these effects could be promising for an enhancement of the bonding strength upon gluing as well as for the use of the processed powder as additive to polymer resins. The oxidation of the polymer (a) should happen by the attachment of polar groups, which could then probably act as chemical interlinks between binder and substrate or between composite powder and polymer matrix. The homogeneous etching (b) could lead to exposed ATH particles, allowing an improved attachment of an adhesive or a polymer matrix to the ATH's hydroxyl groups. Thus, these partially exposed filler particles would presumably act as mechanical interlocking and most likely lead to an improved bonding strength via form closure. The inhomogeneous etching (c), that is, the formation of rough micro- and nanostructures, should at least lead to a mechanical interlocking between adhesive and substrate or between composite powder and polymer matrix. However, these expectations were not fulfilled by a DBD pretreatment of PMMA/ATH work pieces. Even though some carboxy groups at the outermost surface layer of the PMMA as well as an increased surface roughness did remarkably reduce the water contact angles, no significant impact on bonding strengths with a water-based adhesive was observed. Due to formation of debris on the surface, representing the weakest link, an increase in bonding strength was prevented. The stability of the bonds against humidity was significantly improved, but still this does not yield any new possibilities for the use of the PMMA/ATH waste powder.

Following these previous results, the results of a plasma treatment of the waste powder using a gliding arc discharge are presented in this contribution. The gas temperatures of gliding arc discharges are usually in the order of magnitude of $1000 \mathrm{~K}$ and above [23], while the increase of sample temperatures during DBD plasma treatments usually would not exceed $10 \mathrm{~K}$ [24]. Correspondingly, the etching rates for the polymer are expected to be significantly higher in comparison to the previous approach. As a result, the formation of significant amounts of debris might be inhibited. Furthermore, the presented approach employs remote plasma to directly process the waste powder within a gas stream and concurrently deposit the powder onto a surface.

Remote plasma devices, that is, plasma jets, already have been employed to deposit films onto PMMA substrates via plasma-enhanced chemical vapour deposition [25]. Furthermore, the use of remote plasma devices for the functionalization of aerosol particles has been demonstrated before, for example, for polyethylene particles [26]. The approach to use remote plasma for both a functionalization of aerosol particles and the concurrent deposition of these particles as a functional coating, however, has not yet been reported in literature.

\section{Characterisation of the Used PMMA/ATH Powder}

In this work, aluminium trihydrate-reinforced poly(methyl methacrylate) powder from Kolpa, d.d., Slovenia, was used for the realisation of PMMA/ATH layers by atmospheric pressure plasma powder deposition. The mechanical properties of original PMMA/ATH composite boards were already investigated by other groups, yielding a density $\rho$ of $1740 \mathrm{~kg} / \mathrm{m}^{3}$ and a filler particle fraction of $50 \mathrm{wt} . \%$ ATH [18], as well as a modulus of elasticity $E$ of approximately $9700 \mathrm{~N} / \mathrm{mm}^{2}$ and a bending strength $S$ of approximately $70 \mathrm{~N} / \mathrm{mm}^{2}$ [17]. In addition, the constant wetting rate angle 
(CWRA), the surface energy, the particle size distribution, and the specific surface areas as well as the glass transition temperature were determined in the present work prior to plasma deposition.

\subsection{Determination of the Constant Wetting Rate Angle} (CWRA) and Surface Energy. For the determination of the constant wetting rate angles of distilled water and diiodomethane drops on the used PMMA/ATH powder, a Krüss Drop Shape Analyser, DSA100, was used. Prior to applying the drops on the samples, the powders were pressed using a hand press Graseby from Specac. In this vein, circular plates with a diameter of $13 \mathrm{~mm}$ and a mass of $275 \pm 5 \mathrm{mg}$ were produced where the pressing time was $10 \mathrm{~s}$ and the pressing pressure was $739.46 \mathrm{~N} / \mathrm{mm}^{2}$. The volume of the applied drops was 1-2 $\mu \mathrm{L}$. The process of applying the drops on the substrates was recorded and each drop was subsequently analysed by a circle fitting method from which the contact angle was calculated. Subsequently, the surface energies were determined using the measuring system's Drop Shape Analyser and an implemented evaluation algorithm according to Owens, Wendt, Rabel, and Kaelble (OWRK) [27], which is based on Young's equation, given by

$$
\gamma_{\mathrm{SG}}=\gamma_{\mathrm{SL}}+\gamma_{\mathrm{LG}} \cos \theta \text {. }
$$

Here, $\gamma_{\mathrm{SG}}$ is the interfacial energy between solid and gas, $\gamma_{\mathrm{LG}}$ between liquid and gas, and $\gamma_{\mathrm{SL}}$ between solid and liquid. According to the OWRK method, the total energy $\gamma^{\text {tot }}$ is the sum of polar $\left(\gamma^{P}\right)$ and disperse $\left(\gamma^{D}\right)$ fraction. Distilled water $\left(\gamma^{\text {tot }}=72.8 \mathrm{mNm}^{-1}, \gamma^{P}=51 \mathrm{mNm}^{-1}\right.$, and $\gamma^{D}=21.8 \mathrm{mNm}^{-1}$ at $\left.T=20^{\circ} \mathrm{C}\right)$ and diiodomethane $\left(\gamma^{\text {tot }}=50.8 \mathrm{mNm}^{-1}\right.$, $\gamma^{P}=0 \mathrm{mNm}^{-1}$, and $\gamma^{D}=50.8 \mathrm{mNm}^{-1}$ at $T=20^{\circ} \mathrm{C}$ ) were used to analyse the constant wetting rate angle on the pressed PMMA/ATH powder pellets and to determine its surface energy. The angles were determined after a transition time of $3 \mathrm{~s}$ after application of the drops since it was visually established that this time interval coincides with the transition from the spreading stage to a constant penetration regime, basically following [28]. All measurements were performed at an environmental humidity of $35 \pm 2 \%$ and a temperature of $22 \pm 1^{\circ} \mathrm{C}$. By this procedure, a constant wetting rate angle of $66.94^{\circ} \pm 0.95^{\circ}$ for distilled water was measured, where the overall surface energy was $49.23 \mathrm{mNm}^{-1}$, given by the sum of the disperse fraction of $40.65 \mathrm{mNm}^{-1}$ and the polar fraction of $8.57 \mathrm{mNm}^{-1}$.

\subsection{Determination of the Particle Size Distribution and Specific} Surface Areas. The particle size distribution of the powder was determined by laser light scattering with the aid of a particle analyser Mastersizer S from Malvern Instruments. A 300RF lens with a QS small volume sample dispersion unit for measuring liquid dispersion was used. The obscuration was adjusted to $12-15 \%$. Powder samples were dispersed in distilled water using an ultrasonic probe. The dispersion was sonicated for 3 minutes prior to the measurement. Particle size distributions typically include $D_{(0.1)}, D_{(0.5)}$, and $D_{(0.9)}$, which represent the percentages of particles (i.e., $10 \%, 50 \%$, and $90 \%$, resp.) below the given size in microns. By applying the above-described procedure, the particle size distribution was determined to $D_{(0.1)}=7.23 \mu \mathrm{m}, D_{(0.5)}=75.66 \mu \mathrm{m}$, $D_{(0.9)}=167.82 \mu \mathrm{m}$, and $D_{(\max )}=301.68 \mu \mathrm{m}$.

The specific surface areas of PMMA/ATH powders were determined via Brunauer-Emmet-Teller (BET) nitrogen adsorption at $77 \mathrm{~K}$ from the adsorption data in the relative pressure interval from $p / p_{0}=0.05$ to 0.3 . For this measurement, a nitrogen adsorption analyser Tristar 3000 from Micromeritics Instruments was used. Prior to the measurements, between 150 and $250 \mathrm{mg}$ of the sample were accurately weighed into sample tubes and degassed overnight at $50^{\circ} \mathrm{C}$ in a vacuum dryer VacPrep 061 from Micromeritics Corporation. In the course of this drying process, the temperature was set to $50^{\circ} \mathrm{C}$ in order to avoid possible thermochemical reactions of the samples. Two replicate measurements were carried out to evaluate the reproducibility. As a result, a BET specific surface of $2.1452 \pm 0.0250 \mathrm{~m}^{2} / \mathrm{g}$ was determined.

2.3. Determination of the Glass Transition Temperature. The glass transition temperature of the used polymer composite powder was determined by differential scanning calorimetry (DSC). A commercial setup DSC 820 from Mettler-Toledo International Incorporation was used to measure in steps of $10 \mathrm{~K}$ within a temperature range from $-10^{\circ} \mathrm{C}$ to $250^{\circ} \mathrm{C}$. During the measurement, technical nitrogen was used as cover gas. To minimise the influence of impurities and residuals, two heating curves and a cooling curve were recorded sequentially, while only the second heating curve was used for the analysis.

The measured DSC curves are shown in Figure 1, representing the curves of both heating cycles as well as the cooling process in between. A detailed view of the relevant second heating curve is given in Figure 1(b), depicting a glass transition temperature $T_{g}$ of about $120^{\circ} \mathrm{C}$.

The elevated value for the PMMA/ATH in comparison to the literature value of pure PMMA of $105^{\circ} \mathrm{C}$ [29] is most probably due to the interface between the PMMA matrix and the ATH filler particles [30]. Furthermore, the glass transition temperature is dependent on the mobility of the polymer chains within the matrix. Generally, a large number or length of linear polymers' side chains leads to decreased glass transition temperatures, while stiff polymers exhibit low mobility and thus high glass transition temperatures. Accordingly, hard filler particles within the polymer matrix lead to a reduced mobility of the polymer chains and thus the glass transition temperature usually increases with an increasing content of filler material [31].

2.4. Summary of PMMA/ATH Powder Material Properties. To summarise, the material properties of PMMA/ATH powder which was used for atmospheric pressure plasma deposition as presented hereafter are listed in Table 1.

\section{Materials and Methods}

3.1. Atmospheric Pressure Plasma Layer Deposition. In order to synthesise composite PMMA/ATH, both thin and thick 


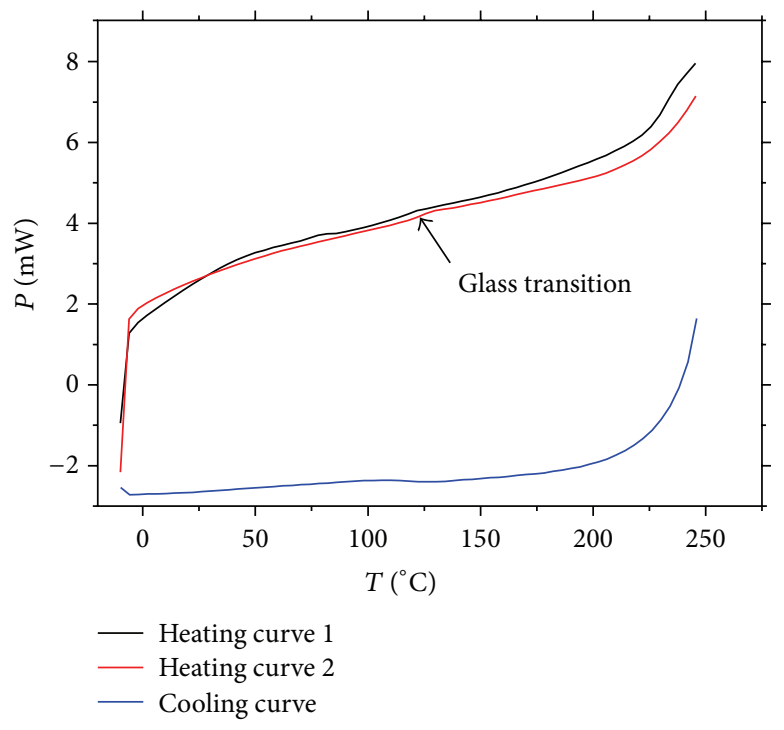

(a)

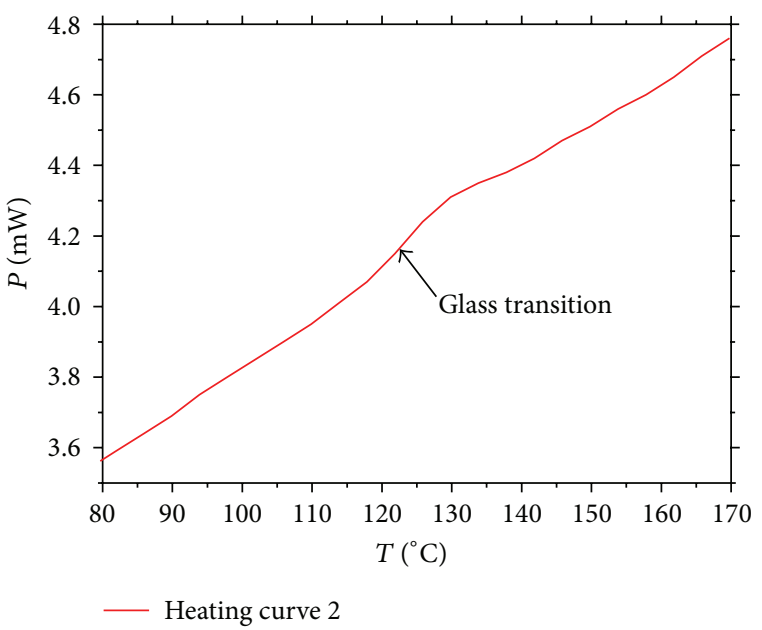

(b)

FIGURE 1: DSC sequential heating and cooling curves for an untreated PMMA/ATH powder (a) as well as a detailed view of the second heating curve (b).

TABLE 1: Material properties of the PMMA/ATH powder used for atmospheric pressure plasma deposition.

\begin{tabular}{lc}
\hline Parameter & Value \\
\hline Ash residue in wt.\% & 53.4 \\
Constant wetting rate angle (CWRA) in & $66.9 \pm 0.95$ \\
degrees & 49.2 \\
Total energy $\gamma^{\text {tot }}$ in $\mathrm{mNm}^{-1}$ & 40.6 \\
Disperse fraction $\gamma^{D}$ of $\gamma^{\text {tot }}{\text { in } \mathrm{mNm}^{-1}}^{\text {tot }} \mathrm{mNm}^{-1}$ & 8.5 \\
Polar fraction $\gamma^{P}$ of $\gamma^{\text {tot }}$ in $\mathrm{mm}$ in $\mu \mathrm{m}$ & 7.2 \\
$D_{(0,1)}$ in $\mu \mathrm{m}$ & 75.6 \\
$D_{(0,5)}$ in $\mu \mathrm{m}$ & 167.8 \\
$D_{(0,9)}$ in $\mu \mathrm{m}$ & 301.6 \\
$D_{(\max )}$ transition temperature $T_{g}$ in ${ }^{\circ} \mathrm{C}$ & 120 \\
\hline
\end{tabular}

films on wood were realised by a thermokinetic coating technique. For this purpose, a customised plasma coating system was used. The entire setup comprises a commercially available plasma power supply and plasma generator Plasmabrush from Reinhausen Plasma GmbH with an optimised spraying nozzle and an aerosol generator as shown in Figure 2. Within the system, plasma process gases are ionised and form a low temperature plasma jet. Concretely, the ignition voltage is approximately $15 \mathrm{kV}$ and the effective voltage is in the range of $2-3 \mathrm{kV}$. The pulse duration amounts to $5-10 \mu \mathrm{s}$, where the pulse repetition rate is $50 \mathrm{kHz}$. Due to the transient nature of the discharge and a low current density, the plasma exhibits moderate temperatures at the exit of the nozzle that furthermore strongly decline along the direction of the gas flow. Depending on the plasma power (the maximum input power is $2 \mathrm{~kW}$ ), the kind of gas, the total gas throughput

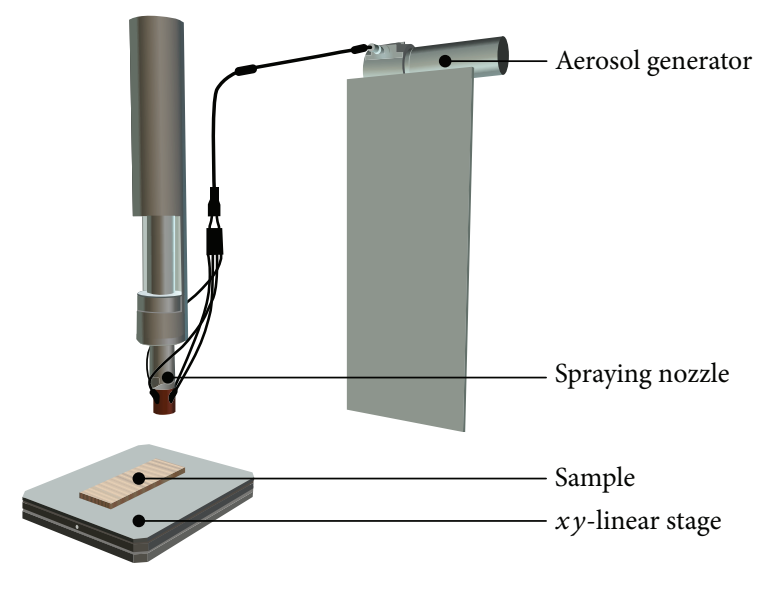

Figure 2: Setup of the used plasma coating system.

(i.e., the plasma process gas and the dispersion carrier gas), and the gas velocity, typical effluent temperatures range from 100 to $200^{\circ} \mathrm{C}$ at a working distance of $10 \mathrm{~mm}$.

Since the starting material was dry PMMA/ATH powder, the implemented aerosol generator was used to dose, disperse, and inject particles into the plasma jet. The powder was sieved previously so that only particles with an initial diameter $<63 \mu \mathrm{m}$ were deposited. $4 \mathrm{~mm}$ thick beech wood samples (Fagus sylvatica L.) were used as substrates and placed on a $x y$-linear stage, where the lateral sample dimension was $76 \times$ $26 \mathrm{~mm}^{2}$. Compressed air (CA) was used as process gas and as carrier gas for the particles. The process gas flow rate and the velocity of the substrate displacement were kept constant at $30 \mathrm{~L} / \mathrm{min}$ and $20 \mathrm{~mm} / \mathrm{s}$, respectively. Different PMMA/ATH layers were deposited by varying the working distance, powder feed rate, and carrier gas pressure as listed in Table 2. 
TABLE 2: Parameter sets for atmospheric pressure plasma deposition of different PMMA/ATH layers.

\begin{tabular}{lccc}
\hline Sample number & $\begin{array}{c}\text { Working } \\
\text { distance in } \\
\text { mm }\end{array}$ & $\begin{array}{c}\text { Powder feed } \\
\text { rate in } \mathrm{cm}^{3} / \mathrm{h}\end{array}$ & $\begin{array}{c}\text { Carrier gas } \\
\text { pressure in } \\
\text { bar }\end{array}$ \\
\hline A & 15 & 10 & 2 \\
B & 13 & 18.1 & 1.5 \\
C & 13 & 18.1 & 2 \\
\hline
\end{tabular}

\subsection{X-Ray Photoelectron Spectroscopic (XPS) Analysis of} Chemical Composition. In order to determine the chemical composition of deposited PMMA/ATH coatings, X-ray photoelectron spectroscopy (XPS) was carried out at room temperature with a base pressure of $5 \times 10^{-8} \mathrm{~Pa}$ using a PHI 5000 VersaProbe II system from ULVAC-PHI. The sample surface was irradiated with an X-ray spot of $200 \mu \mathrm{m}$ in diameter, consisting of monochromatised X-ray photons (1486.8 eV with $0.26 \mathrm{eV}$ FWHM), originating from the $\mathrm{Al} \mathrm{K}_{\alpha}$ line. Photoelectrons emitted from the sample surface were recorded via a spherical capacitor analyser. The resulting spectra were then displayed as binding energy-dependent electron intensities, where the binding energy is given with respect to the Fermi level. Broadening effects within the system add up to a total energy resolution of $<0.5 \mathrm{eV}$ (FWHM Ag3 $\mathrm{d}_{5 / 2}$ ). All spectra were recorded in constant energy mode at a pass energy of $23.5 \mathrm{eV}$ with a step size of $0.1 \mathrm{eV}$. During the measurement, charging effects were compensated via an electron flood gun $(<1 \mathrm{eV})$, running simultaneously with a low-energy $(10 \mathrm{eV}) \mathrm{Ar}^{+}$-gun.

The spectral deconvolution was carried out using the evaluation software MultiPak, where charge referencing was done by means of carbon at $284.8 \mathrm{eV}$. For quantitative analysis, sensitivity factors with correction for the analyser work function (corrected RSF) were applied after Shirley-type background correction. For the peak fitting procedure, Voigt profiles with a Lorentzian contribution of $0-22 \%$ were used in order to achieve the best agreement between experimental data and the mathematical fit. For the quantitative analysis, a total error, that is, a superposition of both the measurement and the fitting error, of 5\% was assumed.

3.3. Confocal Laser Scanning Microscopic (CLSM) Analysis of Topography. For the investigation of the surface topography of the deposited PMMA/ATH layers, confocal laser scanning microscopy (CLSM) was performed using a Keyence VKX210 microscope with a VK-X200K controller. The wavelength of the laser used for illumination amounts to $408 \mathrm{~nm}$. The CLSM's total magnification $m_{\text {tot }}$ can be set up by varying the objective lenses $\left(m_{\mathrm{ol}}=10 \mathrm{x}, 20 \mathrm{x}, 50 \mathrm{x}\right.$, and 150x) and applying the microscope's internal magnification (10x), an $8 \mathrm{x}$ optical zoom, and further digital magnification. The possible total magnification then amounts to $200 \mathrm{x}$ to $24,000 \mathrm{x}$. The images shown in this contribution were recorded using objectives with a magnification of $10 \mathrm{x}(\mathrm{NA}=0.3)$ or $150 \mathrm{x}(\mathrm{NA}$ $=0.95$ ), with all of them being superpositions of widefield microscopic and laser intensity measurements.
3.4. Determination of Water Contact Angle (WCA). Water contact angle (WCA) measurements on the PMMA/ATHcoated beech samples were performed by using a commercial measuring system G10 from Krüss $\mathrm{GmbH}$, where each sample was measured three times. For this purpose, a droplet $(11 \mu \mathrm{L})$ of distilled water was applied to the surface and recorded for $10 \mathrm{~s}$ (25 frames/sec). For every frame, the contact angle was determined by fitting a circular arc to the droplet and calculating the angle between the solid and the tangent at the point of intersection.

\section{Results and Discussion}

4.1. Chemical Composition of Untreated and Deposited PMMA/ATH. The XPS detail spectra before background subtraction of the $\mathrm{O} 1 \mathrm{~s}, \mathrm{Al} 2 \mathrm{p}$, and $\mathrm{Cls}$ peaks for both untreated powder before deposition and thick powder coating on a beech substrate (sample B) are shown in Figure 3.

It turns out that the $\mathrm{Al} 2 \mathrm{p}$ peak intensity increases significantly after the deposition process. Consistently, the O1s peak is slightly shifted towards lower binding energies. This indicates a decrease of carbon-bound oxygen resulting from PMMA, where the O1s peaks are found at $532.01 \mathrm{eV}$ and $533.57 \mathrm{eV}$, respectively [32]. Apparently, this comes along with an increase of aluminium-bound oxygen, where the O1s peak is located at a binding energy of $531.8 \mathrm{eV}$ [33].

In order to investigate whether the increase in aluminium is due to a decomposition of PMMA, the C1s peaks represented in Figure 3(c) before and after the coating procedure were analysed in more detail as shown in Figure 4.

For this purpose, the distances of the three minor fit peaks were constrained to $0.72 \mathrm{eV}, 1.79 \mathrm{eV}$, and $4.03 \mathrm{eV}$, respectively, to the main peak. This main peak represents the peak of lowest binding energy, hereinafter referred to as MP [32]. Moreover, the ratio of the MP's area $\left(-\mathrm{CH}_{2},-\mathrm{CH}_{3}\right)$ and that of the neighbouring peak $\left(\mathrm{C}-\mathrm{C}_{4}\right)$ were set to 0.5 [32]. Since the plasma coating procedure is expected to induce oxidation processes, the ratios of the peak areas corresponding to carbon atoms bound to oxygen are left unconstrained. The chemical compositions obtained by such spectral dissecting of the C1s peaks of the investigated surfaces, that is, untreated powder before deposition and thick powder coating, are summarised in Tables 3 and 4.

As already shown in Figure 3(b), the amount of aluminium increases in the course of the deposition process whereas the total carbon content decreases. Furthermore, an oxidation process takes place yielding an increased relative amount of carbon as $\mathrm{O}-\mathrm{C}=\mathrm{O}$ compound (carboxy groups). For untreated powder, the resulting ratios of the main $\mathrm{Cls}$ peak's area and the other C1s peak areas are in good agreement with literature [32] as also shown in Table 3. As reported in the literature, the relative amount of methoxy groups is reduced while carboxy groups are increased but to far less extent. Hence, the arc discharge plasma used for the coating process in the present work disposes less oxidative species than the dielectric barrier discharge which was applied. In contrast to that, the resulting coatings exhibit an increased content of aluminium by a factor of about 2.2. Therefore, PMMA seems to be etched, which was also reported in [21] 


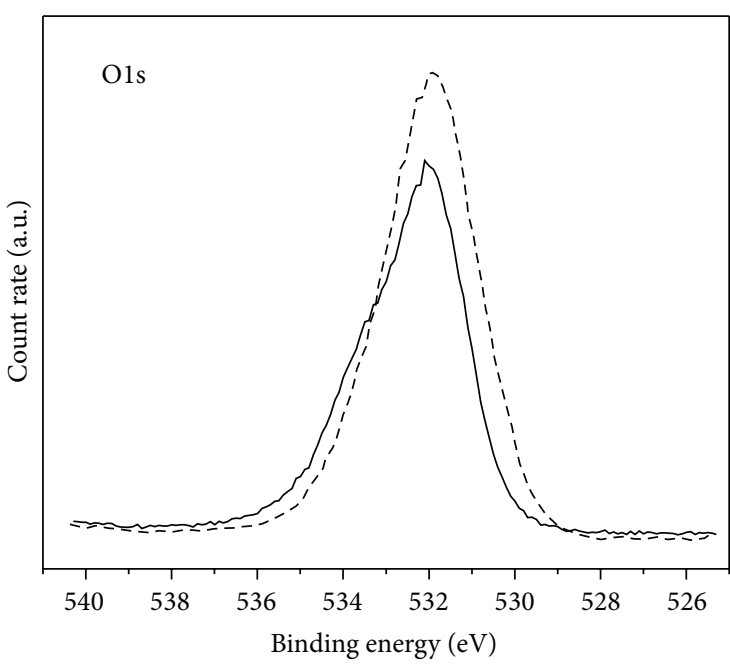

(a)

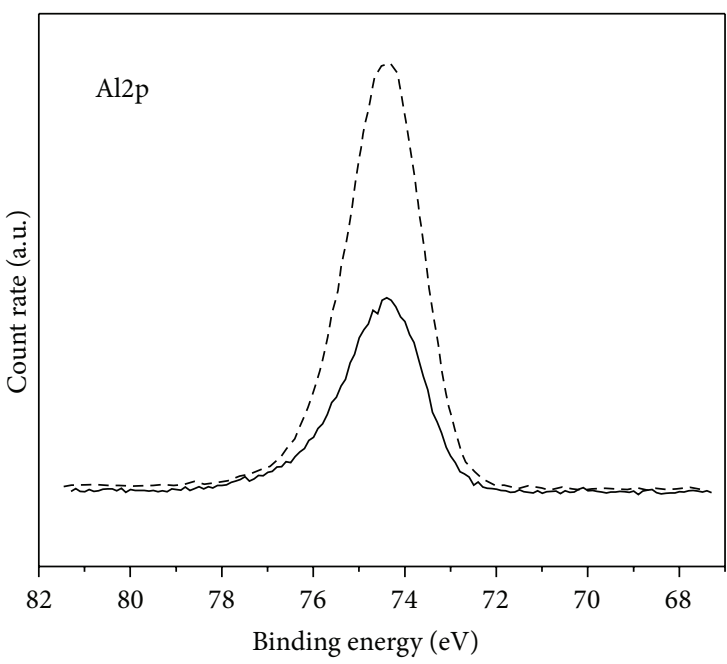

(b)

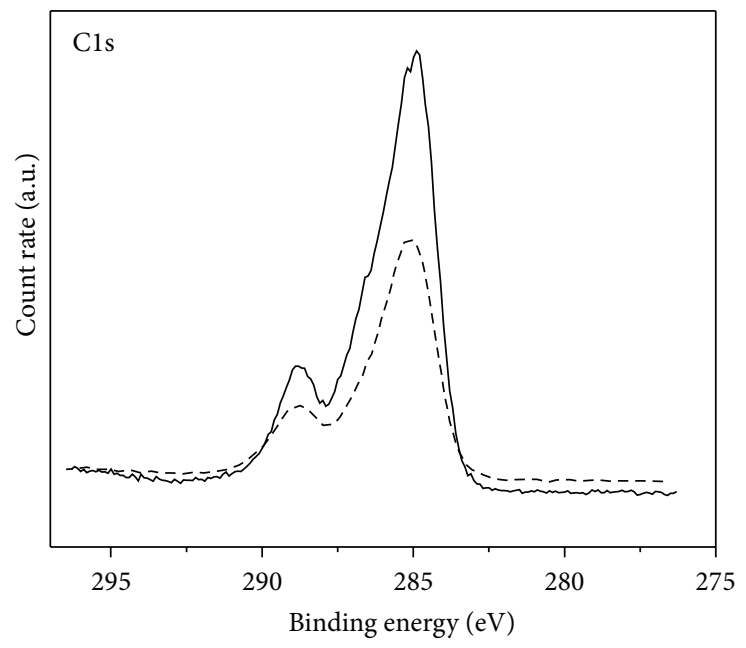

(c)

FIGURE 3: XPS detail spectra of untreated powder before deposition (solid line) and thick powder coating (dashed line). (a) O1s peak, (b) $\mathrm{Al} 2 \mathrm{p}$ peak, and (c) Cls peak.

TABLE 3: Binding energies (BE) of relevant peaks, particular concentration $c_{x}$, and measured relative area $A_{\text {meas }}$ of carbon bonds within the C1s peak as well as literature values for $A_{\text {lit }}$ of the untreated powder before deposition.

\begin{tabular}{lcccc}
\hline Peak & BE in eV & $c$ in at.\% & $A_{\text {meas }}$ in $\%$ & \\
\hline O1s & 532.0 & 37.6 & & \\
Al2p & 74.4 & 7.2 & & \\
Cls & & & & \\
& & & & \\
$-\mathrm{CH}_{2},-\mathrm{CH}_{3}$ & 284.7 & 22.7 & $32]$ & \\
$\mathrm{C}-\mathrm{C}_{4}$ & 285.5 & 11.4 & $20.6\left(=0.5 \cdot \mathrm{MPA}{ }^{1}\right)$ & $42.0(=: \mathrm{MPA})$ \\
$-\mathrm{O}-\mathrm{CH}_{3}$ & 286.5 & 11.9 & $21.5(=0.5 \cdot \mathrm{MPA})$ & $21.0(=0.5 \cdot \mathrm{MPA})$ \\
$\mathrm{O}-\mathrm{C}=\mathrm{O}$ & 288.8 & 9.3 & $16.8(=0.4 \cdot \mathrm{MPA})$ & $21.0(=0.5 \cdot \mathrm{MPA})$ \\
\hline
\end{tabular}

${ }^{1} \mathrm{MPA}=$ main peak area.

(cf. Introduction), and aluminium compounds are uncovered during the coating process whereas, apparently, the chemical composition of PMMA is not significantly modified. This is also confirmed by the ratios of the particular concentrations obtained from each considered peak after and before the plasma coating process $c_{c} / c_{p}$. Here, $c_{c}$ is the concentration of plasma-deposited material and $c_{p}$ is the concentration of the untreated powder corresponding to the values given in Tables 3 and 4 . Figure 5 shows a radar chart of the investigated peak ratios $c_{c} / c_{p}$. On the one hand, the data in Figure 5(a) confirm 


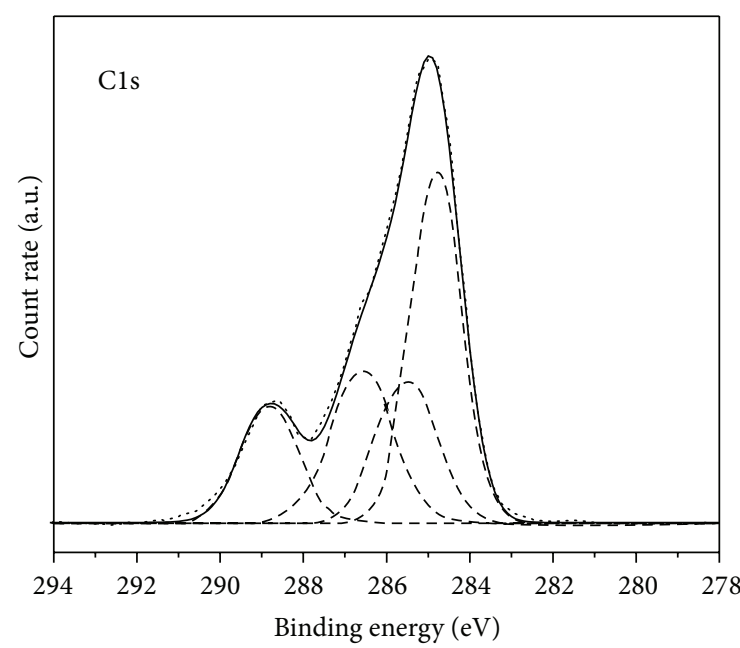

(a)

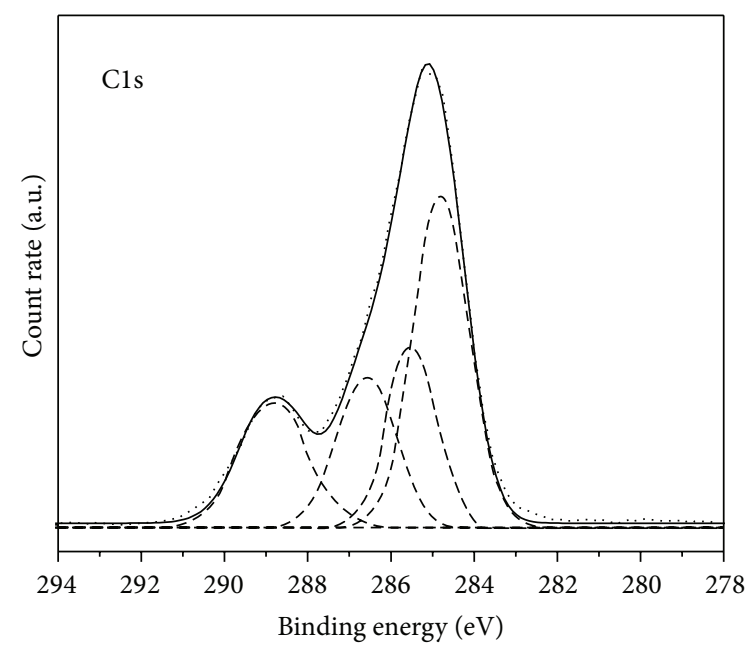

(b)

FIGURE 4: Measured Cls peaks of (a) untreated powder before deposition and (b) thick powder coating (dotted lines) including fits (dashed lines) for particular bonds and cumulative fit (solid lines).

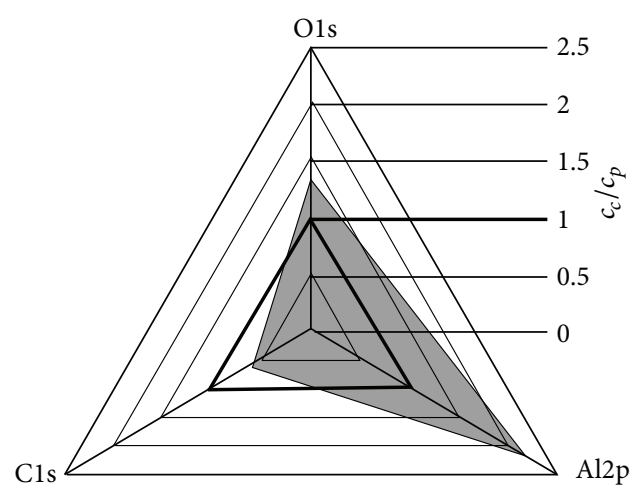

(a)

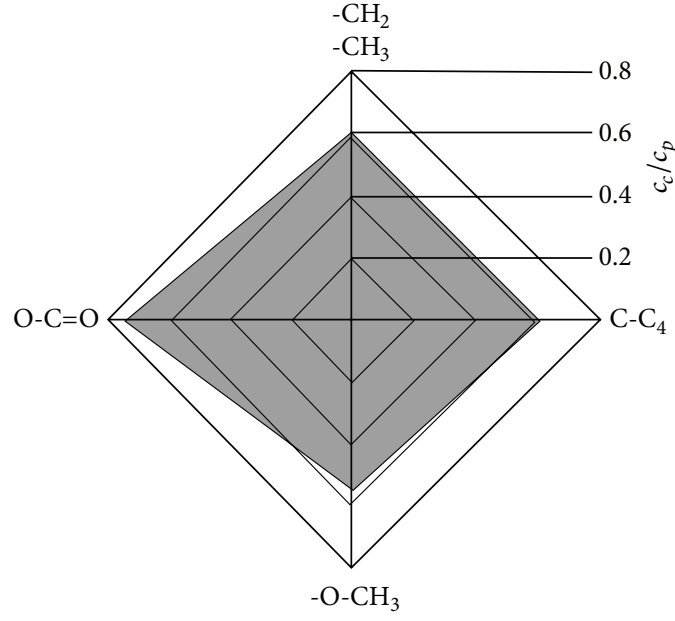

(b)

FIGURE 5: Radar chart of the ratios of particular concentrations obtained from each considered peak after and before the plasma coating process $c_{c} / c_{p}$.

TABLE 4: Binding energies (BE) of relevant peaks, particular concentration $c_{x}$, and measured relative area $A_{\text {meas }}$ of carbon bonds within the Cls peak of thick powder coating.

\begin{tabular}{lccc}
\hline Peak & BE in eV & $c$ in at.\% & $A_{\text {meas }}$ in $\%$ \\
\hline O1s & 531.94 & 50.5 & \\
$\mathrm{Al} 2 \mathrm{p}$ & 74.30 & 15.6 & \\
$\mathrm{Cls}$ & & & \\
$-\mathrm{CH}_{2},-\mathrm{CH}_{3}$ & 284.78 & $13.8(=: \mathrm{MPA})$ & $40.6(=: \mathrm{MPA})$ \\
$\mathrm{C}_{-} \mathrm{C}_{4}$ & 285.50 & $6.9(=0.5 \cdot \mathrm{MPA})$ & $20.3(=0.5 \cdot \mathrm{MPA})$ \\
$-\mathrm{O}-\mathrm{CH}_{3}$ & 286.57 & $6.4(=0.46 \cdot \mathrm{MPA})$ & $18.9(=0.46 \cdot \mathrm{MPA})$ \\
$\mathrm{O}-\mathrm{C}=\mathrm{O}$ & 288.81 & $6.9(=0.50 \cdot \mathrm{MPA})$ & $20.2(=0.5 \cdot \mathrm{MPA})$ \\
\hline
\end{tabular}

the decrease in carbon, the increase in aluminium, and the oxidation of the powder. On the other hand, Figure 5(b) reveals that, irrespective of an increase of carboxy groups, the composition of the $\mathrm{Cls}$ peak is not significantly changed by the plasma coating process.

The uncovered aluminium compounds are expected to feature a better ability to develop chemical bonds, for example, with waterborne adhesives, than the original material with a surface mainly composed of PMMA. This is also indicated by the wettability behaviour of deposited PMMA/ATH coatings as discussed hereafter in Section 4.3.

4.2. Topography. The CLSM images of a thin plasma coating on beech wood in Figure 6(a) (top and middle image) consist of superimposed widefield microscopic and laser intensity measurements. The sample is partially covered with patches of the composite polymer material while still large areas of the substrate are exposed as shown in the top image. The bottom 


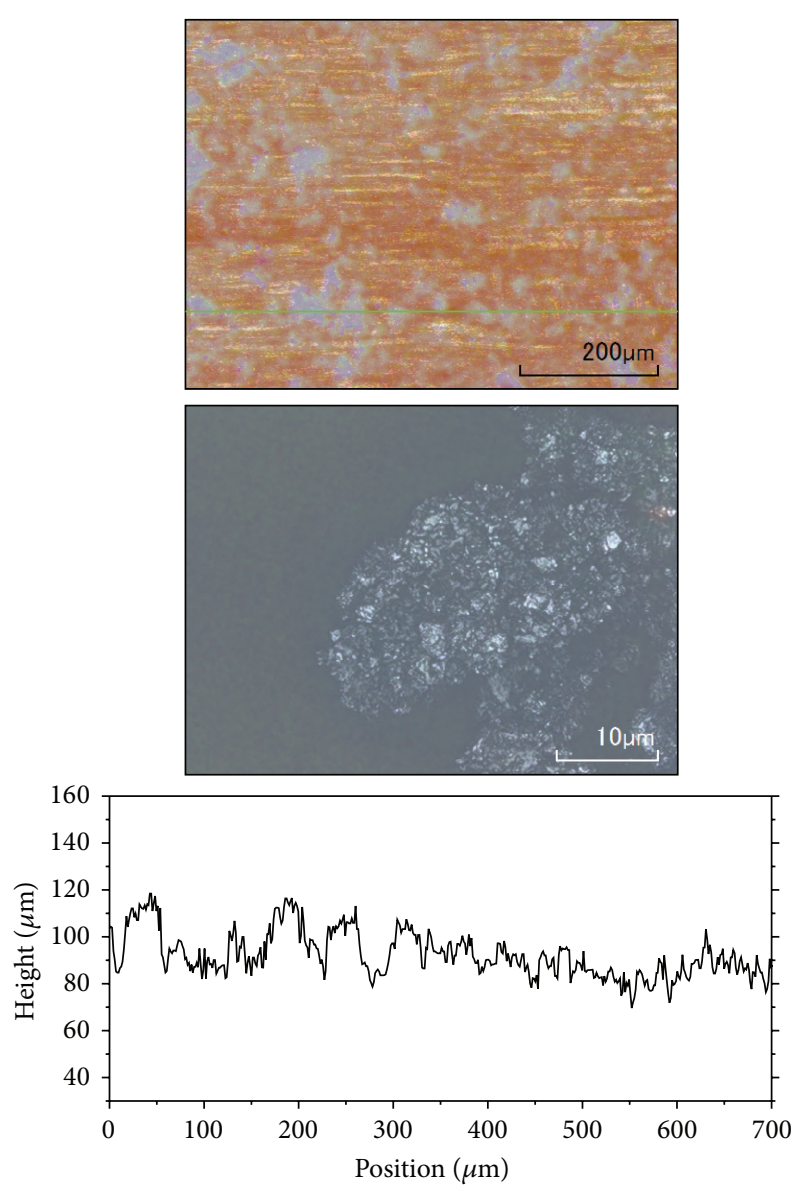

(a)
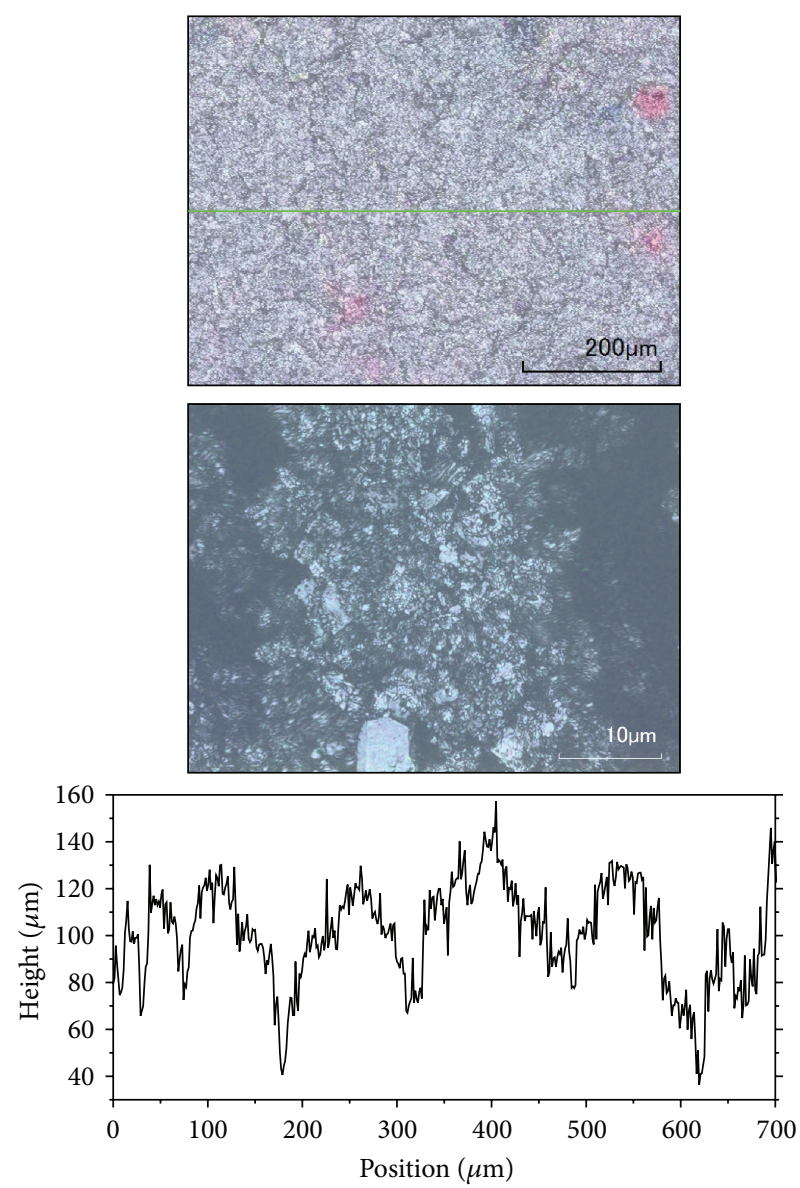

(b)

FIGURE 6: (a) CLSM images of a thin plasma coating on a beech wood substrate (sample A) at optical magnifications of 100x (top) and 1500x (middle) as well as a height profile along the green line within the top image. (b) CLSM images of a thick plasma coating on a beech wood substrate (sample C) at optical magnifications of 100x (top) and 1500x (middle) as well as a height profile along the green line within the top image.

images display the height profile along the green line within the top image. The height of these patches amounts to about $20 \mu \mathrm{m}$ according to several of these CLSM line scans. The root means square (RMS) surface roughness $R_{\mathrm{RMS}}$ amounts to $12.5 \mu \mathrm{m}$ for the overall area shown in the top left image. On top of the white patches, the roughness evaluation yields values of $5-8 \mu \mathrm{m}$, while the uncovered substrate areas exhibit a RMS roughness of approximately $3 \mu \mathrm{m}$. A magnified detail picture of one of the white patches is additionally shown in the middle, revealing it to be roughly structured from differently sized particles.

Figure 6(b) shows images of a thick PMMA/ATH coating on beech wood as superimposed widefield microscopic images (top and middle) as well as a line profile (bottom image) along the green line within the top image. As visible in the top image, the surface is completely covered with the deposited composite polymer material. The red spots are due to residuals from differently coloured powder of the same base material. The magnified detail picture (middle) reveals a rough structure with differently sized, separate particles just as for the partially coated sample. The bottom image depicts the height profile along the green line within the top image. This line scan shows elevations with diameters of around $100 \mu \mathrm{m}$ and heights of approximately $30-100 \mu \mathrm{m}$, which are not correlated with the structure of the underlying beech wood substrate. The RMS roughness amounts to $R_{\mathrm{RMS}}=$ $25.2 \mu \mathrm{m}$, thus encouraging the visual impression of a heavily ragged coating.

The presence of separate particles within both coatings is rather surprising, since the glass transition temperature of the PMMA/ATH powder was determined to be about $120^{\circ} \mathrm{C}$. The gas temperatures within the active region of the plasma device usually exceed $1000^{\circ} \mathrm{C}$, while the remote plasma mostly exceeds the given glass transition temperature, even at a distance of $10 \mathrm{~mm}$ from the plasma jet nozzle (cf. Section 3.1). Considering the retention time of the particles within the hot gas stream, the particle temperatures should well exceed the glass transition temperature, too, and thus the deformation of the particles as well as the mobility of the polymer chains should be large enough to assure an interdiffusion of the polymer chains and thereby the film formation process. However, the particles obviously did 


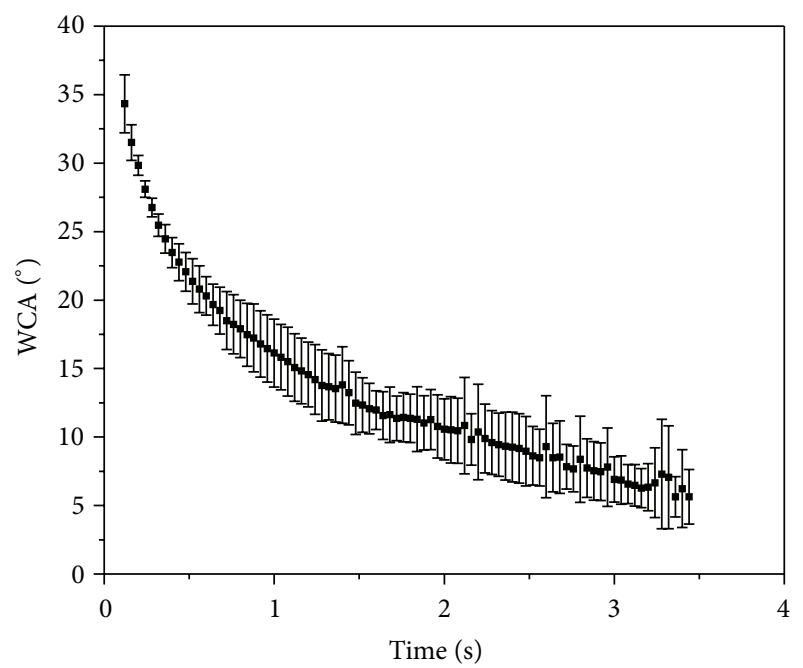

(a)

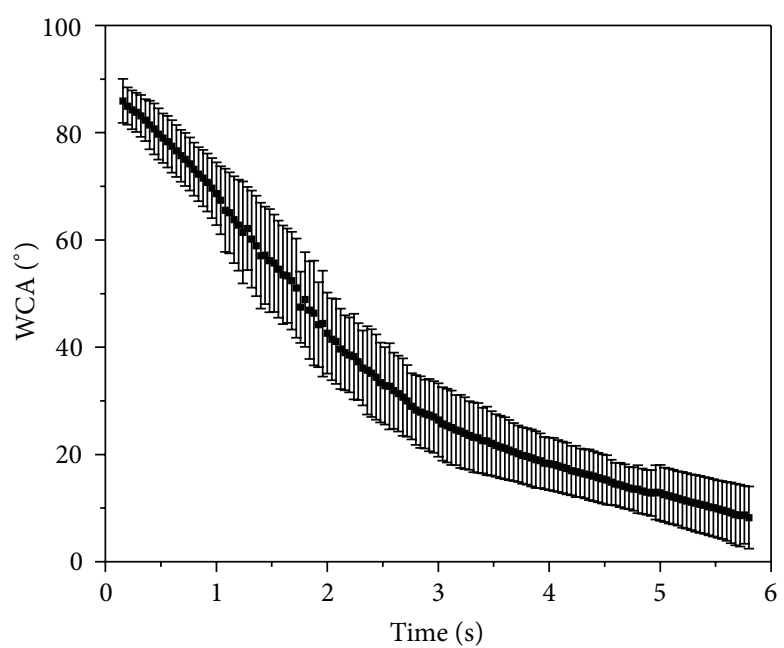

(b)

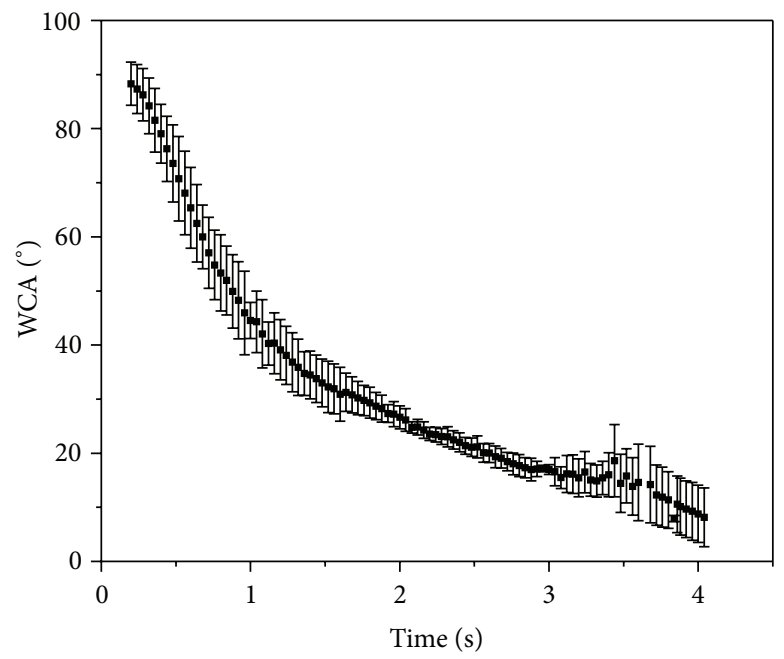

(c)

Figure 7: Evolution of the water contact angles for (a) thin coating (sample A) and thick coatings: (b) sample B, (c) sample C.

largely neither deform in shape nor form a closed film. Even though this should happen even for slightly cross-linked polymers, further experiments showed that, at temperatures as high as $200^{\circ} \mathrm{C}$, no interdiffusion takes place for the used PMMA/ATH composite material. This might most likely be due to the chemical bonds between the PMMA and the ATH via the used functional silane-based surfactant. These findings also fit very well to the high temperature resistance of PMMA and the nearly temperature-independent modulus of elasticity up to thermal decomposition of the polymer [34]. Furthermore, there might be an influence due to the effects of the plasma treatment beyond the heat transfer, for example, the etching of the PMMA polymer. A significant formation of cross-links can be excluded from the XPS results since, here, no notable changes in the bonding structure of the carbon compounds could be determined (cf. Figures 4 and 5). Even though there is still a significant amount of PMMA left after the plasma treatment, the assumed polymer etching leads to a considerably increased fraction of the filler particles as compared to the polymer matrix (cf. Section 4.1). Thus, the glass transition temperature should further increase [31]. The main etching mechanism is the generation of short, volatile oligomers via chain scission [35], which might possibly also lead to the formation of residual short-chained oligomers at the particle surfaces. The interdiffusion and film formation processes, however, depend strongly on the interface between the PMMA/ATH particles and might therefore be significantly hindered by an adlayer of short-chained oligomers.

4.3. Wettability. The evolution of the water contact angles versus time is represented in Figure 7. For each time interval, the average of the three measurements was plotted. As a cutoff, the shortest time of complete soaking was used. This point in time represents the limit of measurability which is found 
at a water contact angle of $<5^{\circ}$. Each droplet was completely soaked by the material within the measuring period of $10 \mathrm{~s}$, illustrating a high wettability of the plasma-deposited PMMA/ATH coatings. Generally, the contact angles for the thin coating (Figure 7(a), cf. also Figure 6(a)) are smaller than for the thick coatings (Figures 7(b) and 7(c), cf. also Figure 6(b)) for all time intervals. This is supposed to be caused by a surface activation of the substrate itself, that is, beech wood, as already reported, for example, by Wolkenhauer and coworkers [36].

In the literature, contact angles for untreated plates were found to be $>60^{\circ}$ and no soaking process was observed. The raw material is thus rather hydrophobic which is generally also valid for pure PMMA. This behaviour is confirmed by the measurements of the constant wetting rate angle on pressed powder pellets before plasma deposition (cf. Section 2.1). Even though a quantitative comparison of the wettability of the PMMA/ATH plates, untreated powder, and the deposited coatings is not possible (which is due to the completely different forms, either in powder form or in solid matter), the highly hydrophilic characteristics of all plasma coatings obviously have to be correlated with a significantly increased polar part of the surface energies. Moreover, diiodomethane droplets $(8 \mu \mathrm{L})$ were applied to study the wettability of the coatings with a nonpolar liquid, but all droplets were soaked almost immediately without yielding measurable contact angles. Hence, the resulting coatings also exhibit highly lipophilic characteristics similar to the starting material.

The improved wettability is in good agreement with the results obtained by XPS. As a result of an uncovering of aluminium compounds, the wettability is enhanced by providing new bonding sites. Furthermore, the rough structure of the surface confirmed by CLSM measurements also supports this effect. In contrast to the literature, the PMMA polymer matrix of the deposited layers is not oxidised by the attachment of polar groups at all, which could contribute to the wettability with water.

\section{Summary and Outlook}

In this work, it was shown that PMMA/ATH raw material and plasma-deposited PMMA/ATH feature notably different material properties. As a main aspect, the XPS investigations suggest that ATH was uncovered by a plasma-induced etching of the PMMA matrix in the course of the plasma deposition process as visualised in Figure 8.

However, based on the given results, it cannot be stated whether the ATH particles are chemically influenced by the plasma process, too, or remain as aluminium hydroxide. A more detailed investigation using Auger electron spectroscopy is planned to be carried out in ongoing work. In any case, the supplementary water contact angle measurements support an uncovering of aluminium-based bonds. In contrast to the raw material which shows a hydrophobic behaviour, the deposited coatings are rather amphiphilic. As a result of this property, the surface energy could not be determined since the analysis of contact angles of dispersed liquids was not possible. It was shown that such high wettability is not caused by the formation of additional polar

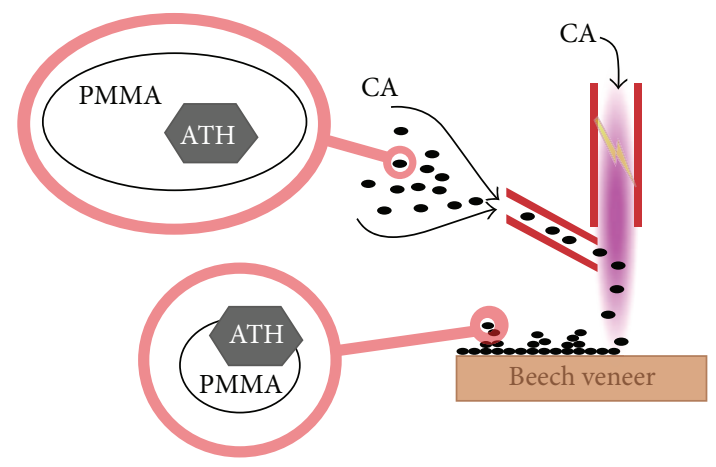

FIgURE 8: Visualisation of the plasma-induced modification of PMMA/ATH by atmospheric pressure plasma powder deposition.

groups, that is, an activation of PMMA, but most likely due to the above-mentioned uncovering of ATH. The observed decrease in carbon, giving rise to such uncovering, is most probably due to a chain scission mechanism from the plasma as described, for example, by Kuzuya and coworkers [35]. Subsequently, the resulting short-chained oligomers would desorb from the PMMA/ATH particles' surfaces. An adjacent oxidation of these hydrocarbon molecules by the plasma towards the formation of $\mathrm{CO}_{2}$ and water is likely but has not been investigated yet.

As shown by CLSM, the plasma deposition does not result in film formation. Thus, completed coatings cannot be realised by simply applying this approach. However, the uncovering of ATH provides further docking points that might improve the adhesion of glues or lacquers. In future projects, the realised coatings could thus be finished by applying either solvent- or water-based lacquers while a complete impregnation of the PMMA/ATH primary coating should be ensured due to its high wettability for polar and nonpolar liquids. In such a multicomposite system, the ATH particles could significantly improve the mechanical properties of the coating as commonly known for inorganic filler particles within polymers [8-10]. Furthermore, the ATH particles should significantly promote the adhesion between both a polar top coat matrix and the PMMA particles, due to form closure as well as due to the ATH particles being chemically bonded to the finish coating and via silane-based surfactants to the PMMA. Another finishing procedure could include a polymerization of further MMA monomers around the deposited coatings in order to maintain the excellent chemical stability and resistance against UV radiation of the raw material. This might even be possible by plasma polymerization via the addition of the MMA monomer (cf. [37]) to the process gas during the PMMA/ATH powderbased primary film deposition, which will be evaluated in a consecutive study. The development of such layer systems involving atmospheric pressure plasma powder deposition of PMMA/ATH could contribute to sustainable and resourceefficient coating processes since the raw material is recycled from waste, that is, abrasive dust which originates from classical manufacturing of PMMA/ATH work pieces as already mentioned in the Introduction. 


\section{Conflict of Interests}

The authors declare that there is no conflict of interests regarding the publication of this paper.

\section{Acknowledgments}

This work was supported by the German Federal Ministry of Education and Research in the frame of the research project "PlaNaWood," funding reference no. 03X5519B. The authors further thank Frank Endres from the Institute of Electrochemistry at Clausthal University of Technology for the provision of the CLSM, Ulrike Koecher from the Institute of Technical Chemistry at Clausthal University of Technology for the measurement of DSC curves, and Roman Rerich from the University of Applied Sciences and Arts for their help during the experimentation and evaluation as well as Andrej Beličič from Kolpa d.d. for providing the used powder material.

\section{References}

[1] M. Wagner and J. Sellers, "Kinetics of filler-polymer interaction between fine particle silica and SBR or butyl rubber," Industrial \& Engineering Chemistry, vol. 51, no. 8, pp. 961-966, 1959.

[2] H. Zhang, M. Lu, Q. Lu, B. He, L. Zhang, and Y. Liu, "Design and preparation of cross-linked $\alpha$-methylstyrene acrylonitrile copolymer nanoparticles and their interfacial investigation with rubber," Journal of Applied Polymer Science, vol. 132, no. 18, Article ID 41914, 2015.

[3] ISO, "Plastics-decorative solid surfacing materials-determination of properties-sheet goods," ISO 19712-2: 2007, 2007.

[4] R. B. Duggins, C. Ford, H. C. Miller, and E. Vassiliou, "Filled polymethyl methacrylate article and a process for its manufacture," US Patent no. 3,827,933, 1974.

[5] R. B. Duggins and C. Ford, "Use of alumina trihydrate in a polymethyl methacrylate article," US Patent no. 3,847,865, 1974.

[6] C. R. Peters and J. E. Young, "Process for making bowls comprising acrylic plastic filled with alumina trihydrate," US Patent no. 6554944 b1, 2003.

[7] E. Gunel and C. Basaran, "Influence of filler content and interphase properties on large deformation micromechanics of particle filled acrylics," Mechanics of Materials, vol. 57, pp. 134146, 2013.

[8] O. A. Stapountzi, M. N. Charalambides, and J. G. Williams, "Micromechanical models for stiffness prediction of alumina trihydrate (ATH) reinforced poly (methyl methacrylate) (PMMA): effect of filler volume fraction and temperature," Composites Science and Technology, vol. 69, no. 11-12, pp. 20152023, 2009.

[9] C. Basaran, S. Nie, and C. S. Hutchins, "Time dependent behavior of a particle filled composite PMMA/ATH at elevated temperatures," Journal of Composite Materials, vol. 42, no. 19, pp. 2003-2025, 2008.

[10] C. Basaran, S. Nie, C. S. Hutchins, and H. Ergun, "Influence of interfacial bond strength on fatigue life and thermo-mechanical behavior of a particulate composite: an experimental study," International Journal of Damage Mechanics, vol. 17, no. 2, pp. 123-147, 2008.
[11] I. Sobolev and E. A. Woycheshin, "Alumina trihydrate," in Handbook of Fillers for Plastics, H. S. Katz, Ed., Van Nostrand Reinhold, New York, NY, USA, 1987.

[12] H. S. Katz and J. V. Milewski, Handbook of Fillers for Plastics, Van Nostrand Reinhold, New York, NY, USA, 1987.

[13] A. P. Mouritz and A. G. Gibson, "Flame retardant composites," in Fire Properties of Polymer Composite Materials, vol. 143 of Solid Mechanics and Its Applications, pp. 237-286, Springer, Dordrecht, The Netherlands, 2006.

[14] O. Obakponovwe and J. G. Williams, "Temperature effects on the fatigue of highly filled PMMA," Journal of Materials Science, vol. 41, no. 2, pp. 437-443, 2006.

[15] I. M. Joni, T. Nishiwaki, K. Okuyama, S. Isoi, and R. Kuribayashi, "Enhancement of the thermal stability and mechanical properties of a PMMA/aluminum trihydroxide composite synthesized via bead milling," Powder Technology, vol. 204, no. 1, pp. 145-153, 2010.

[16] E. P. Plueddemann, Silane Coupling Agents, Plenum Press, New York, NY, USA, 1991.

[17] V. Jivkov, R. Simeonova, A. Marinova, and G. Gradesva, "Study on the gluing abilities of solid surface composites with different wood based materials and foam PVC," in Proceedings of the 24th International Scientific Conference, pp. 49-55, Zagreb, Croatia, 2013.

[18] E. Šušteršič, M. Tušar, and A. Zupančič Valant, "Rheological and mechanical characterization of waste PMMA/ATH modified bitumen," Construction and Building Materials, vol. 38, pp. 119125,2013

[19] W. Kaminsky, M. Predel, and A. Sadiki, "Feedstock recycling of polymers by pyrolysis in a fluidised bed," Polymer Degradation and Stability, vol. 85, no. 3, pp. 1045-1050, 2004.

[20] M. C. Sunny and C. P. Sharma, "Surface modification of corneal contact lens with phosphoryl choline by glow discharge," Biomaterials, Artificial Cells, and Immobilization Biotechnology, vol. 19, no. 3, pp. 599-612, 1991.

[21] K. Saito and A. Yoshikawa, "O $\mathrm{O}_{2}$ plasma etch rate reduction on synchrotron radiation exposed PMMA films," Japanese Journal of Applied Physics, vol. 26, no. 9, pp. 1428-1430, 1987.

[22] M. C. Coen, R. Lehmann, P. Groening, and L. Schlapbach, "Modification of the micro- and nanotopography of several polymers by plasma treatments," Applied Surface Science, vol. 207, pp. 276-286, 2003.

[23] A. Fridman, S. Nester, L. A. Kennedy, A. Saveliev, and O. MutafYardimci, "Gliding arc gas discharge," Progress in Energy and Combustion Science, vol. 25, no. 2, pp. 211-231, 1999.

[24] U. Kogelschatz, "Dielectric-barrier discharges: their history, discharge physics, and industrial applications," Plasma Chemistry and Plasma Processing, vol. 23, no. 1, pp. 1-46, 2003.

[25] R. Wang, C. Zhang, X. Liu, Q. Xie, P. Yan, and T. Shao, "Microsecond pulse driven $\mathrm{Ar} / \mathrm{CF}_{4}$ plasma jet for polymethylmethacrylate surface modification at atmospheric pressure," Applied Surface Science, vol. 328, pp. 509-515, 2015.

[26] G. Oberbossel, A. T. Güntner, L. Kündig, C. Roth, and P. R. von Rohr, "Polymer powder treatment in atmospheric pressure plasma circulating fluidized bed reactor," Plasma Processes and Polymers, vol. 12, no. 3, pp. 285-292, 2015.

[27] D. K. Owens and R. C. Wendt, "Estimation of the surface free energy of polymers," Journal of Applied Polymer Science, vol. 13, no. 8, pp. 1741-1747, 1969.

[28] R. M. Nussbaum, "Natural surface inactivation of Scots pine and Norway spruce evaluated by contact angle measurements," Holz Als Roh-und Werkstoff, vol. 57, no. 6, pp. 419-424, 1999. 
[29] J. Brandrup, Ed., Polymer Handbook, Wiley, Hoboken, NJ, USA, 4th edition, 1999.

[30] J. Berriot, H. Montes, F. Lequeux, D. Long, and P. Sotta, "Evidence for the shift of the glass transition near the particles in silica-filled elastomers," Macromolecules, vol. 35, no. 26, pp. 9756-9762, 2002.

[31] S. Cerveny, S. N. Goyanes, A. J. Marzocca, and G. H. Rubiolo, "Dynamic properties in aluminum filled PMMA," Polymer, vol. 40, no. 6, pp. 1495-1500, 1999.

[32] G. Beamson and D. Briggs, High Resolution XPS of Organic Polymers. The Scienta ESCA300 Database, Wiley, Chichester, UK, 1992.

[33] J. T. Kloprogge, L. V. Duong, B. J. Wood, and R. L. Frost, "XPS study of the major minerals in bauxite: gibbsite, bayerite and (pseudo-)boehmite," Journal of Colloid and Interface Science, vol. 296, no. 2, pp. 572-576, 2006.

[34] M. J. Forrest, Analysis of Plastics, Smithers Rapra, Shrewsbury, UK, 2002.

[35] M. Kuzuya, A. Noguchi, M. Ishikawa et al., "Electron spin resonance study of free-radical formation and its decay of plasma-irradiated poly(methacrylic acid) and its esters," Journal of Physical Chemistry, vol. 95, no. 6, pp. 2398-2403, 1991.

[36] A. Wolkenhauer, G. Avramidis, E. Hauswald, H. Militz, and W. Viöl, "Sanding vs. plasma treatment of aged wood: a comparison with respect to surface energy," International Journal of Adhesion and Adhesives, vol. 29, no. 1, pp. 18-22, 2009.

[37] T. B. Casserly and K. K. Gleason, "Effect of substrate temperature on the plasma polymerization of poly(methyl methacrylate)," Chemical Vapor Deposition, vol. 12, no. 1, pp. 59-66, 2006. 

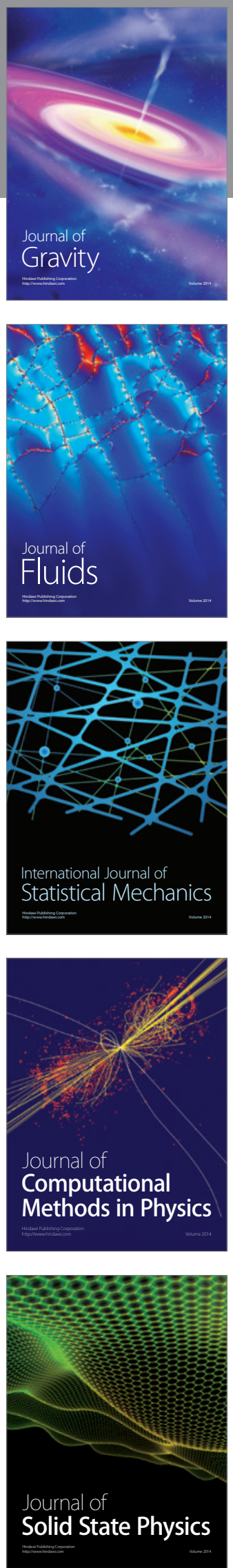

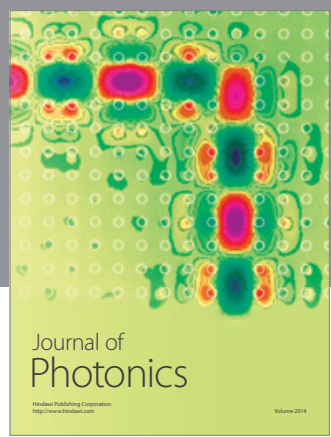

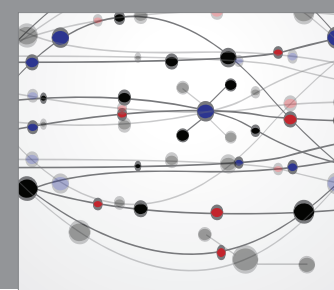

The Scientific World Journal

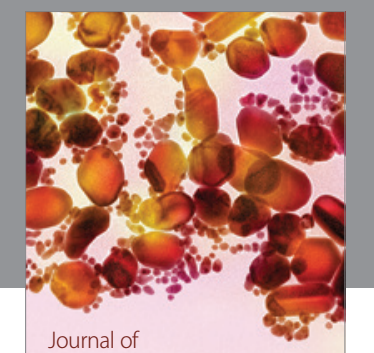

Soft Matter
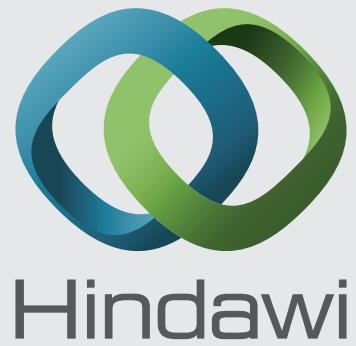

Submit your manuscripts at

http://www.hindawi.com
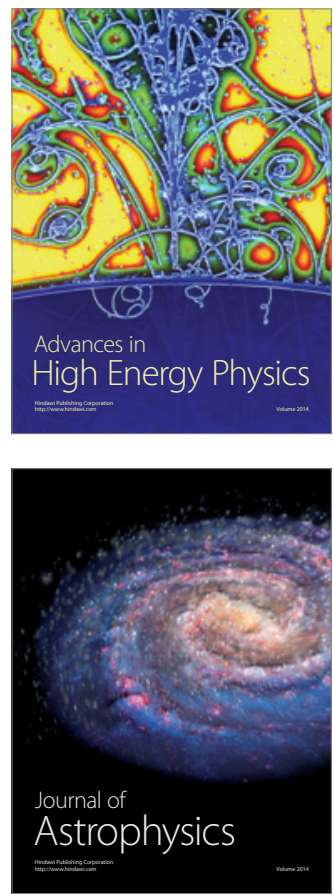
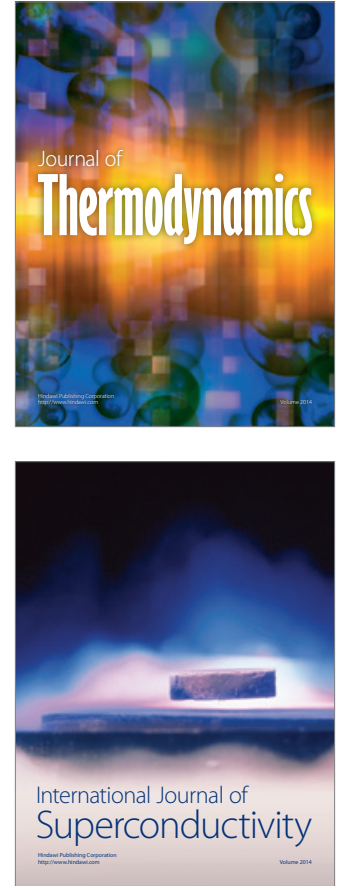
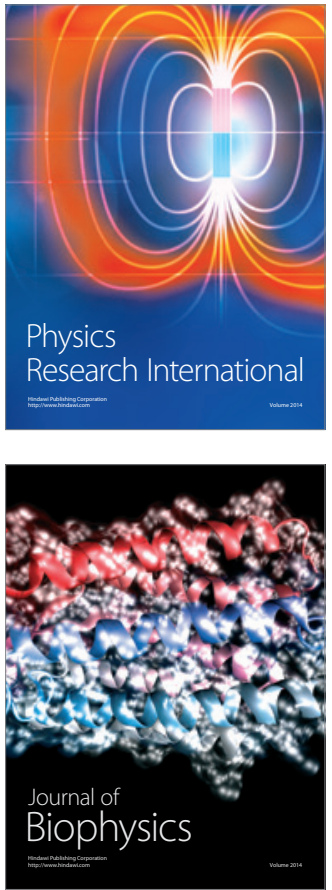
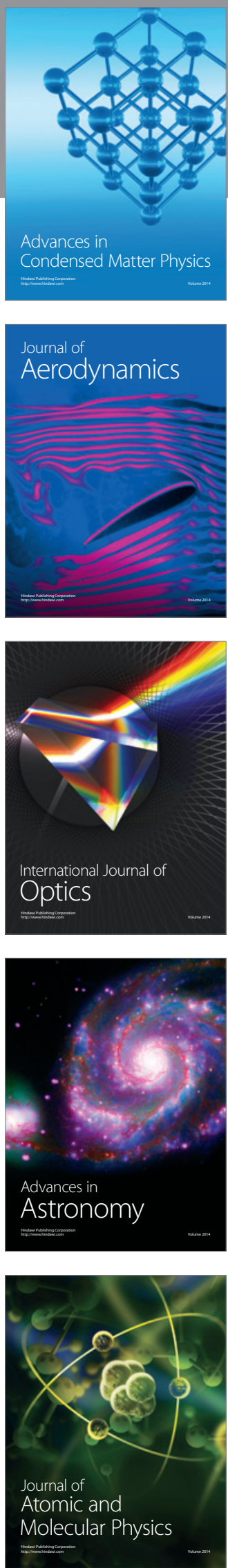